THE POSTGRADUATE

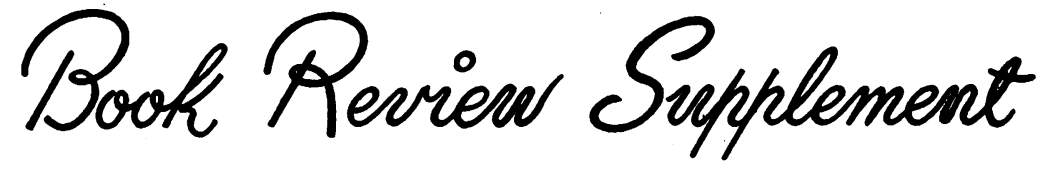

\section{THE MANAGEMENT OF BRONCHIAL ASTHMA}

By H. G. J. Herzheimer, M.D., L.R.C.P.ED., L.R.C.S.ED., L.R.F.P.S.GLAS. Pp. viii +107 , with I6 illustrations. London: Butterworth \& Co. 1952. 22s. $6 \mathrm{~d}$.

In this small book the author has adopted an individual approach and his conclusions are based on the results of his own experimental work. The first four chapters are concerned with definitions and diagnosis, the remaining 80 pages are devoted to advice on treatment. It includes a list of references and some typical case histories. The cost (22s. 6d.) seems to be excessive for so small a book, even by modern standards.

The problems that confront the enquiring practitioner interested in asthma are well set out, and the definitions and discussions of the underlying pathology are clear and comprehensible. The author tries to adopt a critical and scientific attitude to the many difficulties that arise in dealing with the management of asthmatic patients. Although it is evident that his conclusions are based on much hard work, he fails to achieve the high standard he has set himself. The effect is uneven, and in places confusing. Thus after discussing the method of specific desensitization by inhalation of increasing quantities of allergen in the form of an aerosol, he concludes by saying ' It is certain that more experience with the inhalation method is needed and that we are far from the possibility of its universal application. It is equally certain that it is one of our few reliable means of aetiological treatment, unfortunately yet restricted to a minority of cases.' (P. 83.) This paragraph is contradictory; furthermore, a method evidently still in the experimental stage is given too prominent a place in a book designed to help the practitioner. Later in the book the same method of treatment is referred to, stating ' Bronchial hyposensitization by aerosol inhalation offers the possibility of objective assessment.' (P. 97.) 'This is no doubt true, but he overlooks the fact that it is equally possible to assess the effect of treatment with the better-known method of subcutaneaus desensitization by means of exactly the same procedure, i.e., by spirographic tracings of the patient's respiration during exposure to an aerolized preparation of the allergen before and after treatment.

Those interested in asthma will find a great deal of value in this book, but its lack of discrimination limits its usefulness as a guide to practitioners.

\section{MODERN TRENDS IN GASTRO- ENTEROLOGY}

Edited by F. Avery Jones, M.D., F.R.C.P. Pp. xiii +831 , with 275 illustrations. London: Butterworth and Co. 1952. £5 5s.

The present rate of increment to our knowledge in medicine is so great that it is impossible for a single person to keep completely up to date with recent advances save in a comparatively limited sphere. Accordingly the publication of a book which sets out to survey all the new work in the immense field of gastro-enterology immediately promises to be of the greatest value, and one's expectation is heightened when the editor of the volume is so eminent an authority as Dr. Avery Jones. It can be said at once that such expectations are amply fulfilled, and that admiration and gratitude are plentifully due to the editor and his collaborators for this most interesting and stimulating volume.

The book is not intended to be a comprehensive ? textbook of gastro-enterology. Its purpose ' is to bring together recent work in the gastro-enterological aspects of medicine and surgery,' and in this it eminently succeeds. The particular value of the work lies in the fact that the many sections cover not only advances in the practical clinical management of gastro-enterological disorders, but also much recent work on more theoretical aspects of the subject such as gastric secretion, fat absorption, pancreatic secretion and other subjects of fundamental physiological importance.

Written as they have been by experts in their fields the multiplicity of subjects have been lucidly and fully covered. Faced by such a distinguished collection of contributors as Witts, Aird, Norman Tanner, Illingworth, Cuthbert Dukes, Lloyd-Davies and Sherlock to mention but a few it is but invidious to single out any particular section for especial comment, but it is impossible to refrain from noting the outstanding articles by Belsey on diaphragmatic hernia, by Hardy and Brooke on ulcerative colitis and by Avery Jones on haematemesis and melaena.

Any detailed criticism of a work of this size is, of course, impossible and would be impertinent from a single reviewer. It is, perhaps, a little disappointing to find no reference at all to intestinal obstruction and only little to proctology, when 30 pages are devoted to diseases of the salivary glands, with no discussion of the modern work on the anatomy of the facial nerve in its relation to excision of tumours of the parotid gland. Further, 